\title{
Modelo de gestion empresarial basado en el emprendedorismo para micro empresas que permita su ascenso como pequeñas empresas
}

\author{
Business management model based on entrepreneurship for micro-enterprises that \\ allows its ascent like small-enterprises
}

\section{INTRODUCCIÓN}

La actividad empresarial ha sido y será la mejor forma de luchar contra la pobreza y en ese campo las empresas privadas cumplen un rol principal y determinante. Las Microempresas (MYPES) de acuerdo a todas las estadísticas oficiales representan más del $98 \%$ entre las empresas del departamento de Junín, sin embargo, a pesar de ser unidades empresariales generadoras de empleo, producción e impuestos, etc, no tienen gran aporte a la economía regional o nacional, porque la mayoría del empleo que generan es empleo sin mayores beneficios sociales, el aporte al PBI es pobre toda vez que el rubro en el cual se ubican es de comercio y servicios.

En cuanto a la generación de impuestos, de acuerdo a la SUNAT, tampoco son relevantes del total de impuestos que genera la empresa privada; por ejemplo, a nivel nacional se sabe que todas las microempresas sólo aportan un promedio del $0,15 \%$ del total de impuestos. Teniendo en cuenta lo anterior podemos afirmar que las MYPES como tal no tienen el aporte relevante como todos desearíamos. Lo ideal en el contexto actual es que las empresas puedan ser un gran dinamizador de la economía, generando empleo de calidad, aportando al PBI y aportando con sus impuestos. En ese sentido, estimo que es imperativo generar las oportunidades micro y macroeconómicas para que las MYPES puedan desarrollarse empresarialmente y ascender hacia Pequeñas y Medianas Empresas (PYMES) para que de esta manera puedan contribuir

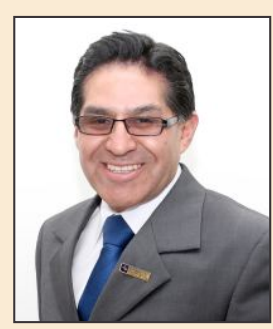

Gustavo Loayza

de manera mucho más relevante no sólo en la economía nacional sino también generando bienestar a los propios promotores de estas unidades empresariales.

La intención de este estudio ha sido demostrar que los modelos de gestión empresarial existentes no han generado un buen desarrollo y desempeño de las MYPES en general y en el distrito de Chilca de la provincia de Huancayo - estudio de caso - en especial; esto por los altos costos de capacitación existentes entre otros.

\section{Antecedentes}

Según Fernando Saboia (1) las características psicológicas y de los proyectos empresariales de una muestra de emprendedores

1 Economista; Coordinador Académico de la Escuela de Economía de la Universidad Continental. 
brasileños que desarrollaron un programa de capacitación emprendedora en el periodo 1997 - 2005, nos permiten afirmar que la continuidad de un proyecto y por ende, el éxito de un proyecto empresarial está determinado por sus características personales, en particular por su espíritu innovador y creativo, así como por su capacidad de auto-evaluación.

También el Dr. Emanuel Ferreira (2) realiza una reflexión sobre la figura del emprendedor - innovador, que fue dejada en la penumbra, durante mucho tiempo, para resurgir con gran fuerza, en la década de los setenta. Pero hoy en día, más que nunca, manifiesta que crear su propio empleo, es fundamental para la sociedad.

El Dr. Francisco Gonzales (3) realiza un análisis etimológico - histórico de la palabra "entrepreneur" y el impacto en la creación de empresas.

Se cuenta con el Documento de Trabajo DTE04-2003 de Centrum Católica (4) en la cual realizan un análisis de factores internos a la empresa y al empresario, agrupando los factores externos como un componente separado del modelo. Entre los factores internos, están las competencias directivas del empresario, competencias esenciales de la empresa, cultura empresarial y gestión estratégica.

Alejandro Indacochea (5) presenta una propuesta de desarrollo de la región del Valle del Mantaro e identifica sus grandes desafíos, oportunidades y debilidades.

La probemática que se aborda en esta investigación, se fundamenta en estadísticas elaboradas por el Ministerio de Trabajo y Promoción del Empleo en el 2008, en el cual se manifiesta que en Lima existía un total de 223977 empresas, de los cuales el 88,8\% corresponde a MYPES, el $9,78 \%$ a PYMES y el $1,4 \%$ a la gran empresa. Esta estructura empresarial no ha variado desde el año de 1990, donde el $87,7 \%$ eran MYPES, el $10,59 \%$ eran PYMES y el $1,69 \%$ era gran empresa, sobre un total de 124095 empresas; es decir, un gran porcentaje de las empresas que eran MYPES en 1990, siguen conservando la misma condición 21 años después.

La contribución de las MYPES a la Población Económicamente Activa (PEA), sólo en Lima Metropolitana fue del $21,4 \%$ del total. Siendo el primero la PEA generada por los trabajadores independientes que representan el $28,1 \%$. Las PYMES generaron el $13,4 \%$ de la PEA, la gran empresa generó el $17,1 \%$ de la PEA y el Estado sólo un 7,6\% (6).

Otro factor a ser considerado en el análisis de las MYPES, es la evolución del Producto Bruto Interno (PBI) con respecto al número de empresas creadas. De acuerdo a los estudios del Colectivo Integral de Desarrollo desde 1990 las empresas crecieron en 204\% y el PBI creció en un $188 \%$. Esto quiere decir que sólo se está logrando un crecimiento paralelo o simétrico entre el número de empresas y el $\mathrm{PBI}$, pero no un impacto o contribución importante de las Mypes en la producción nacional.

También se puede determinar que las MYPES constituyen el 55,85\%, PYMES el $42,43 \%$ y gran empresa son el 1,72\%.

Según el economista Jeffrey Sachs, para lograr que los países salgan de la pobreza se necesitan potenciar los mercados internos para encaminarse por la "escalera del desarrollo". Para ello es necesario que el Estado cree "condiciones previas" de "infraestructuras básicas (carreteras, energía, puertos) y capital humano (sanidad yeducación)".

Realizando un paralelismo con la propuesta, esgrimida por Sachs, desde varios sectores se pretende realizar una apología de las MYPES desde un punto de vista como "Meta nacional", lo cual estimo es un error porque como se ha demostrado con los datos esgrimidos líneas arriba. El mantener MYPES en una misma condición sin permitirles un ascenso hacia PYMES son una gran desventaja competitiva no sólo al país sino también a la localidad, porque: 1) No son generadoras de empleo de calidad, porque 
la mayoría de empleo que genera es familiar y muchas veces son empleos sin las condiciones laborales vigentes; 2) El aporte al PBI también es insuficiente; 3) El aporte a la recaudación fiscal es pobre.

De acuerdo al Censo Económico 2008, se tiene que el departamento de Junín la estructura empresarial no es tan diferente a la ciudad de Lima. Los resultados del Censo Económico 2008, presenta:

Tabla № 01: Clasificación de Empresas en Junín

\begin{tabular}{lrc}
\hline \multicolumn{1}{r}{ Tipo de Empresa } & Q & $\%$ \\
\hline MYPES & 37,042 & 98,86 \\
& 352 & 0,95 \\
PYMES & 75 & 0,20 \\
Gran Empresa & & \\
\hline
\end{tabular}

Fuente: Censo Económico 2008, INEI

Teniendo en cuenta dicha información vemos que las MYPES en la región Junín representan el $98,86 \%$ del total de empresas formales censadas. El presente estudio pretende descubrir las deficiencias en la Gestión Empresarial del empresario MYPE de Huancayo Metropolitano que se convierten en trabas o trampas que impiden su ascenso hacia empresarios PYME. Asimismo se estudiará el impacto de los diferentes segmentos del Macroambiente que impiden que el empresario MYPE ascienda hacia una condición de PYME.

La hipótesis de este trabajo fue, un nuevo modelo de Gestión Empresarial basado en el Emprendedorismo en los empresarios Mypes incidirá en el ascenso empresarial hacia las PYMES en el distrito de Chilca.

La información sobre la población determinada para este estudio fueron proporcionadas por la Cámara de Comercio de Huancayo, quienes tienen información del total de empresas que existen en los Distritos de Huancayo, Tambo y Chilca. La población está conformada por el total de empresarios Mype del Distrito de Chilca, siendo un total de 2788 empresas; de los cuales los que tienen una condición de Empresas Mypes, según el último Censo Económico del INEI, en Junín es del 98,88\%, representando un total de 2754 empresas familiares. Los datos se muestran en la figura 01.

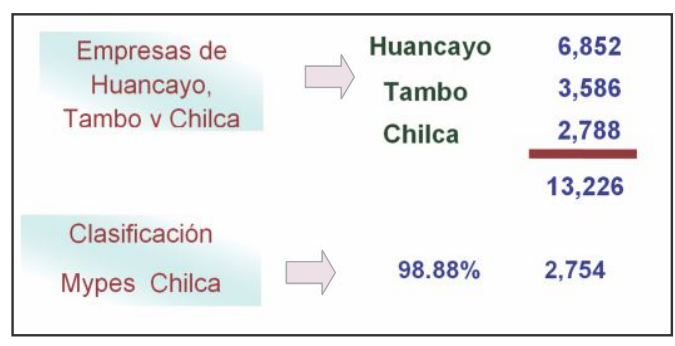

Figura Nº 01: Empresas de Huancayo Metropolitano

La muestra del estudio estuvo formado por 73 empresarios MYPE del distrito de Chilca en la provincia de Huancayo.

\section{Perfil del emprendedor del distrito de Chilca}

De acuerdo a los diferentes estudiosos del Emprendedorismo consultados en el presente estudio se ha consolidado un Perfil del emprendedor Ideal, que está enmarcado con la hipótesis del presente estudio.

Las características de este perfil se detallan en la Tabla № 03.

De acuerdo a los resultados de la investigación realizada entre los empresarios MYPE del distrito de Chilca y contrastándolo con los resultados de la investigación se observa que el perfil emprendedor del empresario MYPE coincide con el Perfil ideal en un $60 \%$. Lo que nos lleva a indicar que el empresario MYPE de Chilca tiene limitaciones para convertirse en un empresario PYME, también nos indica que las restricciones sobre estos empresarios vendrían a ser: Mayor perseverancia, visión de futuro, capacidades de liderazgo y la responsabilidad con actitudes emprendedoras. También se sabe que el $29 \%$ de los empresarios MYPES tienen la misma condición hace más de 10 años y un 31\% 
hace más de 5 años.

De acuerdo a los resultados de la investigación entre los empresarios MYPE del distrito de Chilca, podríamos afirmar que el modelo de gestión empresarial que ellos desarrollan actualmente no les permitiría el ascenso hacia empresas PYME.

\section{CONCLUSIONES}

De acuerdo a los resultados de la investigación también podríamos afirmar que el empresario MYPE del distrito de Chilca tiene sus propias características entre las cuales podemos destacar:

a.El modelo de gestión empresarial desarrollado por los empresarios MYPE del distrito de Chilca adolece de actitudes como: perseverancia, visión de futuro, liderazgo y responsabilidad. Lo que se ha convertido en un lastre para que éstas empresas sigan creciendo y ascendiendo hacia empresas tipo PYMES.

b. En un $50 \%$ son empresarios que tienen más de 5 años bajo la misma condición. Es decir empezaron como empresas MYPES, y continúan siendolo.

c. Sólo un $25 \%$ ha definido una figura jurídica formal que les permita la oportunidad de seguir creciendo o ascendiendo empresarialmente.

d. En un $85 \%$ la inversión inicial fue entre un rango de S/. 1 000,00 a S/. 5 000,00.

e. En un $90 \%$ se dedican al giro de Comercio y Servicios como actividad económica principal.

f. En un $60 \%$ declaran tener estudios superiores ya sean universitarios o técnicos concluidos.

g. El $57 \%$ declara haber recibido capacitación los últimos meses un temas principalmente de tributación.

Tabla № 03: Perfil de Emprendedor Ideal

\begin{tabular}{|c|c|c|c|}
\hline Nro & Concepto & Internacionales & Nacionales \\
\hline 1 & Asumir Riesgos & $\begin{array}{l}\text { Cantillón, Say, Knight, } \\
\text { Mises, Menger, Schalke, } \\
\text { Garzón, Varela }\end{array}$ & MTPE, UCCl, Sánchez \\
\hline 2 & Creativo e Innovador & $\begin{array}{l}\text { Schumpeter, Thunen, } \\
\text { Weber, Betancourt, Varela }\end{array}$ & $\begin{array}{l}\text { MTPE, Linares, UCCl, } \\
\text { USIL }\end{array}$ \\
\hline 3 & Buscador de Oportunidades & $\begin{array}{l}\text { Cantillón, Clark, Kirzner, } \\
\text { Menger, Garzón, } \\
\text { Betancourt, Varela }\end{array}$ & UCCl, Sánchez \\
\hline 4 & Perseverante, Luchador & Garzón, Betancourt, Varela & $\begin{array}{l}\text { MTPE, Linares, UCCI, } \\
\text { Arellano, USIL }\end{array}$ \\
\hline 5 & $\begin{array}{l}\text { Propietarios de Capital } \\
\text { - Ahorradores }\end{array}$ & $\begin{array}{l}\text { Fisiócratas, Smith, Turgot, } \\
\text { Mises }\end{array}$ & MTPE, UCCI, Sánchez \\
\hline 6 & Visión de Futuro & Betancourt, Varela & $\begin{array}{l}\text { MTPE, Linares, UCCI, } \\
\text { Arellano }\end{array}$ \\
\hline 7 & Confianza en si mismo & Garzón, Betancourt, Varela & MTPE, Arellano \\
\hline 8 & Laborioso, Trabajador & Betancourt & $\begin{array}{l}\text { MTPE, Linares, Sánchez, } \\
\text { Arellano }\end{array}$ \\
\hline 9 & Líder & Marshall, Betancourt, Varela & Linares \\
\hline 10 & Responsable & Betancourt, Varela & MTPE, UCCI, \\
\hline
\end{tabular}


h. Su actitud frente al riesgo es una característica principal para el $93 \%$ de los empresarios MYPES encuestados.

i. La creatividad como aspecto principal de su actividad empresarial es asumida como muy importante entre el $91 \%$ de los empresarios MYPE.

i. Para el $31 \%$ de ellos el futuro depende solamente de ellos, en un $21 \%$ de ellos y de su familia y en un $26 \%$ de ellos y de sus colaboradores.

k. El $76 \%$ de los empresarios generaron ingresos ahorrando y trabajando los cuales lo dedicaron para su inversión inicial.

I. El destino de las utilidades en un $51 \%$ fueron orientados al ahorro en el sistema financiero y el $37 \%$ reinvirtieron en sus empresas.

m. Un $86 \%$ no confía en el Estado y en sus instituciones.

n. El $85,3 \%$ confía en si mismo.

o. Un $71 \%$ indica que dedica a sus labores empresariales entre 9 y 12 horas al día.

p. El $66 \%$ de los empresarios busca que sus colaboradores desarrollen actitudes

Tabla Nº 04: Comparación del Perfil ideal con el Perfil del Empresario de Chilca

\begin{tabular}{|c|c|c|}
\hline Nro & Perfil Ideal & $\begin{array}{l}\text { Perfil Empresario } \\
\text { Chilca }\end{array}$ \\
\hline 1 & Asumir Riesgos & $\begin{array}{l}\text { Asume Riesgos } \\
\text { Calculados }\end{array}$ \\
\hline 2 & Creativo e Innovador & Creativo \\
\hline 3 & $\begin{array}{l}\text { Buscador de } \\
\text { Oportunidades }\end{array}$ & $\begin{array}{l}\text { Buscador de } \\
\text { Oportunidades }\end{array}$ \\
\hline 4 & Perseverante, Luchador & \\
\hline 5 & $\begin{array}{l}\text { Propietarios de Capital } \\
\text { - Ahorradores }\end{array}$ & Ahorradores \\
\hline 6 & Visión de Futuro & \\
\hline 7 & Confianza en si mismo & $\begin{array}{l}\text { Confianza en } \\
\text { si mismo }\end{array}$ \\
\hline 8 & Laborioso, Trabajador & $\begin{array}{l}\text { Laborioso, } \\
\text { Trabajador }\end{array}$ \\
\hline 9 & Líder & \\
\hline 10 & Responsable & \\
\hline
\end{tabular}

independientes.

q. El $53 \%$ de los empresarios estuvieron en algún momento en sistemas de centrales riesgos.

r. El $100 \%$ de los empresarios declaran que les hubiera gustado haber nacido en otros países.

s. El $57 \%$ indica que empezaron con su empresa como resultado de sus deseos de independencia, y el 33\% como continuidad empresarial.

\section{REFERENCIAS BIBLIOGRAFICAS}

1. Saboia F, Cruz N. Los Rasgos Psicológicos del Emprendedor y la Continuidad del Proyecto Empresarial: Un Estudio Empírico de Emprendedores Brasileños. Universidade Federal do Ceará. Documento de trabajo número 11/06. 2011.

2. Ferreira E. El Fenómeno de la Doctrina del Emprendedorismo (proceso de emprendimiento) y la Incubación de Empresas-Creando Riquezas.

3. Gonzales DF. Creación de Empresas. Ediciones Pirámide. 2006.

4. Pinto TH, Mazzotti GJ, Barraza JC. La Competitividad en la Pequeña y Microempresa en el Perú: Análisis Estructural del Sector y Lineamientos Estratégicos.

5. Indacochea A. Junín Competitivo: Valle del Mantaro. Centrum Católica. 2005.

6. Instituto Nacional de Estadística e Informática. Encuesta Nacional de Hogares sobre condiciones de vida en el Perú.Lima: INEl; 2008.

Correo electrónico:

gloayza@continental.edu.pe 